\title{
Hidroksisinamik Asit Türevlerinin Canlı-Dışı Helicobacter Pylori Karşıtı Etkileri ile Üreaz Enzimini Engelleme Etkinliklerinin Araştırılması
}

\author{
Sinem 0ktem-0kullu ${ }^{1}$, Nesteren Mansur ${ }^{2} \odot$, Erkan Mozioglu ${ }^{3} \odot$, Meltem Kolgazi ${ }^{4} \odot$
}

${ }^{1}$ Acıbadem Mehmet Ali Aydınlar Üniversitesi, Tıbbi Mikrobiyoloji, İstanbul, Türkiye

${ }^{2}$ Acıbadem Mehmet Ali Aydınlar Üniversitesi, Sağlık Bilimleri Enstitüsü Medikal Biyoteknoloji Programı, İstanbul, Türkiye

${ }^{3}$ Acıbadem Mehmet Ali Aydınlar Üniversitesi, Tıbbi Mikrobiyoloji, İstanbul, Türkiye

${ }^{4}$ Acıbadem Mehmet Ali Aydınlar Üniversitesi, Fizyoloji, İstanbul, Türkiye

Sinem Oktem-0kullu, Dr. Öğr. Üyesi Nesteren Mansur, MSc Erkan Mozioglu, Dr. Öğr. Üyesi Meltem Kolgazi, Dr. Öğr. Üyesi

Illetişim:

Dr. Öğr. Üyesi Sinem Oktem-0kullu Acıbadem Mehmet Ali Aydınlar Üniversitesi, Tıbbi Mikrobiyoloji, İstanbul, Türkiye Tel: +905545874828

E-Posta: sinem.oktem@acibadem.edu.tr

Gönderilme Tarihi : 08 Nisan 2019

Revizyon Tarihi : 01 Temmuz 2019 Kabul Tarihi : : 23 Ağustos 2019
ÖZET

Helicobacter pylori (H. pylori), insanlarda, gastrit, peptik ülser, gastrik kanser ve mukoza ilintili lenfoid doku lenfoması gibi ciddi mide hastalıklarına yol açan önemli bir hastalık etkenidir. H. pylori, ürettiği üreaz enzimleri sayesinde üreyi, karbondioksit ve amonyağa parçalayarak mide çeperinin asidik koşullarını normal pH'ya getirip hayatta kalabildiği için bu bakterilerle vücudun savaşımı kolay değildir. H. pylori enfeksiyonları için antibiyotikler mevcut olsa da antibiyotik direnci gelişimi nedeniyle bu tedaviler sonuçsuz kalabilmekte ve yen antibiyotiklere gereksinim her geçen gün artmaktadır.

Hidroksisinamik asit türevleri basit fenolik asitler olup meyvelerde, meyve çekirdeklerinde ve sebzelerde bulunmaktadır. Ferulik asit, kafeik asit, p-kumarik asit, sinapik asit, sözü edilen bu fenolik asit grubuna ait olup antioksidan, anti-inflamatuvar, antimikrobiyal özelliklere sahiptir ve bu nedenle bazı bakteri enfeksiyonlarının tedavisinde, ilaçlara seçenek olarak kullanılmaktadır. Bu çalışmamızda, bu üç fenolik asidin H. pylori üzerindeki antimikrobiyal etkinliği ve ürez enzimini engelleme etkisi araştııldı.

Hidroksisinamik asit türevlerinin anti-H. pylori etkisi H. pylori G27 standart suşu üzerinde test edildi. Minimum inhibisyon konsantrasyonu (МіK), değerleri 512 ila 0,5 ug/mL arasında değiştiği seri tüp seyreltme yöntemiyle, minimum bakterisidal konsantrasyon (MBK) değerleri ise MiK içinde kullanılan aynı konsantrasyonlarda canılı ve ölü bakterilerin nispi oranının hesaplanması ile belirlendi. MiK için CLSI M07-A9, MBC için CLSI M26-A protokolleri kullanıldı. Ureaz inhibisyon aktivitesi Helicheck, üreaz aktivitesine özgü indikatörlü besiyerinde ölçülmüştür.

H. pylori'ye karşı test edilen tüm bileşikleriçin MiK $64 \mathrm{ug} / \mathrm{mL}$ ve MBK $128 \mathrm{ug} / \mathrm{mL}$ idi. Test edilen bileşiklerin H. pylori tarafindan salgılanan üreaz enzimi üzerinde hiçbir inhibisyonu saptanmadı. Nükleotid salma deneyi sonuçlarına göre, hidroksisinamik asit türevlerinin bakteri zarında hasara sebep olması ile zarda oluşan deliklerden dışarı salınma eğiliminde olması beklenen herhangi bir nüklotit miktarı ölçülememiştir.

Gerçekleştirilen bu çalışma, literatür taramalarımız doğrulutusunda, hidroksisinamik asit türevlerinin anti-H. pylori aktivitesini gösteren ilk çalışmadır. Bu bileşiklerin anti-H. pylori üzerindeki etki mekanizmasını anlamak için daha ileri analizlere ihtiyaç vardır.

Anahtar sözcükler: H. pylori, Anti-H. pylori Etki, hidroksisinamik asit türevleri, üreaz iđnhibisyon, nüklotid salınım testleri

IN VITRO ANTI-HELICOBACTER PYLORI EFFECTS OF HYDROXYCINNAMIC ACID DERIVATIVES AND THEIR UREASE INHIBITION STUDIES ON H. PYLORI UREASE ENZYME

ABSTRACT

Helicobacter pylori (H. pylori) is a human pathogen that can persist in the stomach of infected people for their life spans. It causes chronic gastric inflammation leading to serious gastric diseases such as gastritis, peptic ulcers, gastric cancer and mucosa-associated lymphoid tissue lymphoma. To colonize in the acidic environment of the stomach, H. pylori produces urease enzyme that catalyzes the hydrolysis of urea to yield into ammonia and carbon dioxide. This enzyme neutralizes the acidic environment of the gastric lumen, and gives the bacteria a short-term survival in this highly acidic environment. There are numerous antibiotic-based therapies for the treatment of $H$. pylori infection. However, antibiotic resistance has a significant impact on the failure of these treatments.

Hydroxycinnamic acid derivatives are simple phenolic acids, found mainly in cereals, fruits, seeds of fruits and vegetables. Ferulic acid, Caffeic acid, p-Coumaric acid, and Sinapic acid belong to this phenolic acid group. These derivatives act as antioxidant, anti-inflammatory, antimicrobial agents and have been used for the treatment of some bacterial infections as alternatives to drugs.

The objective of this study was to investigate the anti-H. pylori and urease enzyme inhibitory effects of Ferulic acid, Caffeic acid, p-Coumaric acid and Sinapic acid.

The effect of hydroxycinnamic acid derivatives was tested on $H$. pylori standard train G27. MIC was determined by serial tube dilution method in which the final concentration ranged between 512 to $0.5 \mu \mathrm{g} / \mathrm{ml} \mathrm{and} \mathrm{MBC} \mathrm{was} \mathrm{determined} \mathrm{by} \mathrm{calculating} \mathrm{the} \mathrm{relative} \mathrm{proportion}$ of live and dead bacteria with the same concentration range used in MIC. For MIC, the CLSI M07-A9and for MBC CLSI M26-A protocols were used. Urease inhibitory activity was detected by Helicheck, H. pylori-specific growth media shows urease activity by changing the color of the media. Nucleotide release was measured by spectrophotometry. The MIC was $64 \mu \mathrm{g} / \mathrm{ml}$ and MBC was $128 \mu \mathrm{g} / \mathrm{ml}$ for all compounds and they had no effect on urease enzyme. There was no detectable nucleotide release from the bacterial membrane because of the hydroxycinnamic acid derivatives damage.

As a result, to the best of our knowledge, it is the first report that shows anti-H. pylori activity of the hydroxycinnamic acid derivatives. Further analyses are needed to understand the action mechanism of these compounds on anti-H. pylori property.

Keywords: H. pylori, anti-helicobacter pylori effect, hydroxycinnamic acid derivatives, urease inhibition, nucleotide release assay 
H elicobacter pylori (H. pylori) is asidik mide ortamında başarıyla yerleşebilen en önemli insan hastalık etkenlerinden biridir ve genellikle erken çocukluk evresinde öpüşme, tükürük, mikrop ile bulaş gıda ve suların tüketimi, ebeveynler ile aynı çatal-kaşık kullanımı, gastroskopi sırasında aletlerin yeterince steril edilmemesi gibi yolları ile kazanılmaktadır; tedavi edilmezse kişilerin yaşamları boyunca varlığını sürdürebilmektedir (1). Bugün, dünya nüfusunun yarıdan fazlasına bulaştığı tahmin edilmekle birlikte belirti göstermezken bulaştığı kişlerin \%20 'sinde, peptic ülser, kronik gastrit, mukoza ilintili lenfoid doku lenfoması (MALT) gibi ciddi mide-bağırsak hastalıklarının temel risk etkeni olarak tanımlanmaktadır (2). Aynı zamanda, idiopatik trombositopenik purpura, demir eksikliği kansızlığı ve B12 vitamini eksikliği gibi sindirim hastaIıkları ile de ilintilidir (1). Dünya Sağlık Örgütü (DSÖ) tarafından, $H$. pylori 1. sınıf karsinojen olarak tanımlanmaktadır. Gelişmekte olan ülkelerde, $H$. pylori enfeksiyonlarının yaygınlığı gelişmiş ülkelerden fazladır ve bu oran Türk yetişkin nüfusu için \%70-80'dir. Türkiye'de, çocukların serolojik yaygınlığının \%43,9-53,9 olduğu bildirilmektedir (3).

H. pylori enfeksiyonunun giderilmesi için, proton pompası engelleyicisiyle birlikte en az iki antibiyotiğin birlikte verilmesi gerekmekte ve bu tedavinin başarı oranı \%80'lerde kalmaktadır (4). Ayrıca, ilaçların yan etkileri, zayıf uyum ve antibiyotiklere direnç gelişminin gözlenmesi ek sorunlar getirmektedir. Tedavi için tedavisinde yeni antibiyotiklere gereksinim duyulan bakterilerin yer aldığı DSÖ’nün son yayımladığı listede, klaritromisin dirençli $H$. pylori yüksek öncelikli grup içerisine dâhil edildiği göz ününe alındığında $H$. pylori dahil tüm bu dirençli bakterilerin ilaca direnç gelişim sorunlarının üstesinden gelebilmek için, doğal ürünler başta olmak üzere yeni moleküllerin keşfedilmesi yönündeki çabalar büyük önem taşımaktadır (5).

Mide mukozasında H. pylori'nin yerleşmesi, bakterinin hareketi, üreaz enzim üretimi ve tutunmadaki başarısı ile ilgilidir (6). Üreaz enzimin yardımıyla, $H$. pylori yüksek asidik mide ortamında, kısa süreli bir yaşamda kalma şansı yakalar. Bunun yanı sıra, hareket yeteneği, mide mukozasının daha yönsüz pH'ındaki alanlara doğru bakterinin hızlı bir şekilde ilerleyebilmesine olanak verir. Üreazın bulunmaması halinde $H$. pylori, 4,0-8,0 aralığındaki pH'larda yaşayabilir.

Ancak, üreaz enzimi sayesinde, üre, karbondioksit (CO2) ve amonyağa (NH3) parçalanarak midenin asitliğini azaltarak bu bakterilerin, 2,5 gibi çok düşük pH'larda bile yaşayabilmesini olanaklı hale getirirler. Amonyak H+iyonlarının alıcısı olarak iş görmesinin yanı sıra monokloramin gibi yerleştiği konak hücreler üzerinde zehir etkisi gösteren amonyak türevlerinin oluşmasına öncülük eder. Tüm bu sebeplerden ötürü üreaz enzimi, $H$. pylori için tedavisinde kullanılacak yeni ilaçların önemli bir hedefi olarak düşünülmekte ve bu enzimi engelleyici yeni moleküllerin keşfedilmesi bu araştırmaların en önemli stratejisini oluşturmaktadır (7). Bu sebeple, $H$. pylori enfeksiyonlarının iyileştirilmesinde, dirimbilimsel olarak etkin doğal kökenli ürünlerin üreaz engelleyicisi olma potansiyelleri araştırılmaktadır (8).

Hidroksisinamik asit türevleri, meyvelerde, sebzelerde, tahıllarda ve meyve çekirdeklerinde değişen miktarlarda bulunan polifenolik bileşenlerinin önemli bir grubunu temsil etmektedir (Tablo 1). Hidroksisinamik asit türevlerinden olan kafeik asit birçok meyvede baskın olarak bulunmaktadır; erik, elma, kayısı, yabanmersini ve domateste bulunana toplam hidroksisinamik asit türevlerinin \%75'ini oluşturmaktadır. Bunu ile birlikte p-kumarik asit, turunçgillerin ve ananasın baskın hidroksisinamik asitidir. Hidroksisinamik asitler, bağlı formda geniş ölçüde bulunurlar ve nadiren serbest formda bulunurlar. Meyve ve sebzelerin işlenmesi (donma, sterilizasyon ve fermentasyon) bu tür ürünlerdeki serbest hidroksisinamik asitlerin oluşumuna katkıda bulunur. Klorojenik asit elma, kayısı, çilek, şeftali, armut, erik, avokado ve havuç gibi birçok

Tablo 1. Bazı meyve ve bitkilerin fenolik bileşik içeriği

\begin{tabular}{|c|c|c|}
\hline Tür & $\begin{array}{l}\text { Fenolik içerik } \\
(\mathrm{mg} / 100 \mathrm{~g})\end{array}$ & Kaynaklar \\
\hline $\begin{array}{l}\text { Yaban Mersini } \\
\text { (Vaccinium myrtillus) }\end{array}$ & 525 & (9) \\
\hline $\begin{array}{l}\text { Böğürtlen } \\
\text { (Rubus fruticosus) }\end{array}$ & $\begin{array}{c}361 \\
417-555\end{array}$ & $(10,11)$ \\
\hline $\begin{array}{l}\text { Siyah Frenk Üzümü } \\
\text { (Ribes nigrum) }\end{array}$ & $\begin{array}{c}318,15 \\
498-1342\end{array}$ & $(12,13)$ \\
\hline $\begin{array}{l}\text { Mavi Yemiş } \\
\text { (Vaccinium corymbosum) }\end{array}$ & $\begin{array}{l}181,1-473 \\
261-585\end{array}$ & $(9,14)$ \\
\hline $\begin{array}{l}\text { Çilek } \\
\text { (Fragaria ananassa) }\end{array}$ & $\begin{array}{c}317,2-443,4 \\
102\end{array}$ & $(15,16)$ \\
\hline $\begin{array}{l}\text { Ahududu } \\
\text { (Rubus ideaus) }\end{array}$ & $\begin{array}{c}113,73-177,6 \\
192-359 \\
517 \\
330\end{array}$ & $(17-20)$ \\
\hline $\begin{array}{l}\text { Turna Yemişi } \\
\text { (Vaccinium macrocarpon) }\end{array}$ & $\begin{array}{l}120-176,5 \\
315\end{array}$ & $(21,22)$ \\
\hline $\begin{array}{l}\text { Kekik } \\
\text { (Origanum vulgare subsp. hirtum) }\end{array}$ & 1175,72 & (23) \\
\hline $\begin{array}{l}\text { Nane } \\
\text { (Mentha spicata) }\end{array}$ & 1000,89 & (23) \\
\hline $\begin{array}{l}\text { Adaçayı } \\
\text { (Salvia tomentosa) }\end{array}$ & 1144,93 & (23) \\
\hline $\begin{array}{l}\text { Kantaron } \\
\text { (Hypericum perforatum) }\end{array}$ & 515,8 & (23) \\
\hline
\end{tabular}


gıdada bulunur. Klorojenik asit, özellikle elmalar ve armutlarda enzimatik esmerleşme için anahtar substrattır. Armut kabuğunun kızarması sırasında içeriği \%20 azalır.

Kafeik asit, ferulik asit, p-kumarik asit, sinapik asit ve rosmarinik asit, antioksidan, anti-inflamatuvar ve antimikrobiyal etkileri olduğu bilinen bu önemli fenolik asit grubunun üyelerindendir (Şekil 1). Bu bileşenlerin, doğal yaşamlarında, bitkilerin kokularının, lezzetlerinin ve renklerinin oluşumlarından sorumlu oldukları ve onları, mor-ötesi ışınlara karşı virüslere, bakterilere, böceklere ve hatta digger bitkilere karşı korumada rol aldıkları bilinmekle birlikte yangı, şişmanlık ile yağ metabolizması, vücut ağırlığı ile obezite, diyabet ile insulin direnci gibi bazı metabolik belirgeler (semptomlar) üzerinde olumlu etkileri olduğu gösterilmiştir (24).

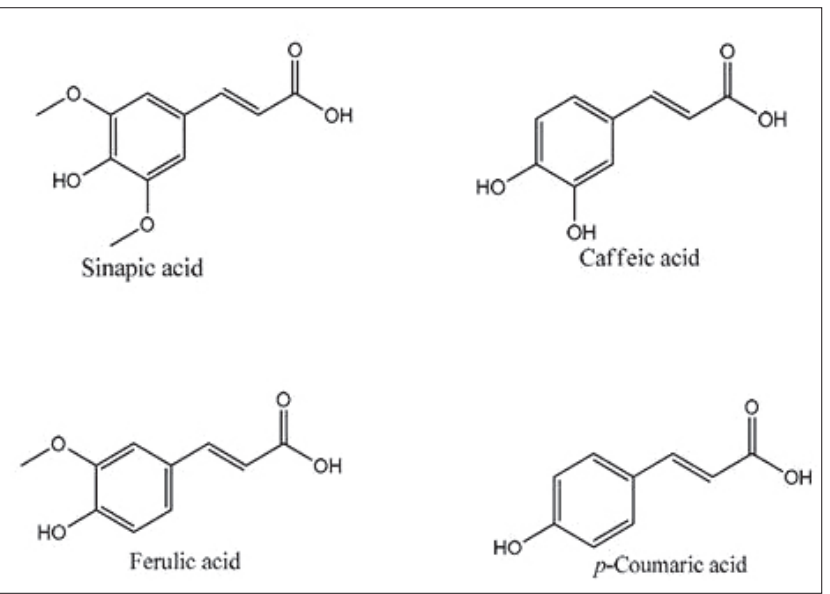

Şekil 1. Hidroksisinamik asitler ve türevleri (25).

Hidroksisinamik asit türevleri, mide ve bağırsak sisteminde kolaylıkla emildikleri ve Gram (+) ve Gram (-) bakteriler üzerinde karşıt etkinlikleri olduğu gösterilmiştir (26). Bununla birlikte, bu bileşenlerin, H. pylori üzerindeki karşıt etkinlikleri henüz gösterilmemiştir. Bu çalışmamızda, ferulik asit, kafeik asit, p-kumarik asit ve sinapik asit gibi dört farklı hidroksisinamik asit türevinin H. pylori'ye karşıt etkinliği ve üreaz enzim etkinliğinin engellenme potansiyeli araştırıldı; bizim bilgimize göre, bu araştırma, bilim yazınındaki (literatüründeki) ilk çalışmadır.

\section{Gereç ve yöntemler}

\section{Hidroksisinamik asit türevleri}

Hidroksisinamik asit türevleri olan ferulik asit (trans4-hydroxy-3-methoxycinnamic acid), kafeik asit (3,4-dihydroxycinnamic acid), p-kumarik asit (trans-4hydroxycinnamic acid) ve sinapik asit (trans-4-Hydroxy3,5-dimethoxy-cinnamic acid) Sigma-Aldrich (Almanya) şirketinden satın alındı.

\section{H. pylori kültürü}

Bu çalışmada kullanılan H. pylori standart soyu G27 Zürih Üniversitesi, Moleküler Kanser Araştırma Enstitüsü'nden Prof. Dr. Anne Mueller'in hediyesidir. H. pylori G27 BD Helicobacter Columbia Agar'da (Becton Dickinson, Germany), mikroaerofilik koşullarda, $37^{\circ} \mathrm{C}$ 'de, 24 saat bekletilerek büyütüldü.

\section{En düşük önleyici derişim (Minimum inhibitör}

konsantrasyonu $=$ MiK)

Bakteriler, Helicobacter Columbia Agar'da, $37^{\circ} \mathrm{C}$ 'de, mikroaerofilik koşullarda, 24 saat boyunca büyütüldü ve daha sonra $10 \%$ FBS (GIBCO) ve 1x Vancomisin (Vancotek, Koçak İlaç, Türkiye) içeren Brucella Broth (Oxoid) besiyerine aktarıldı; burada da aynı koşullarda 24 saat bekletildi. Daha sonra, bakteriler 0,5 McFarland olacak şekilde $(1,5 \times 108$ $\mathrm{cfu} / \mathrm{mL}$ ) seyreltildi. Seyreltilmiş bakteriler, hidroksisinamik asit türevleri dimetil sülfoksit (DMSO) içerisinde çözüldü ve $10 \%$ FBS (GIBCO) ve $1 \times$ Vancomisin (Vancotek, Koçak Illaç, Türkiye) içeren Brucella Broth (Oxoid) besiyerinde iki katlık ardışık seyreltimleri yapıldı; 0,5 McFarland olarak hazırlanmış bakteriler, hidroksisinamik asit türevlerini içeren tüplere ekildi; böylece, kimyasalların son derişimleri, 512 to $0,5 \mu \mathrm{g} / \mathrm{mL}$ oldu. DMSO ise (-) denetim olarak kullanıldı.

Tüpler $37^{\circ} \mathrm{C}$ 'de, 24 saat, mikroaerofilik koşullarda bekletildi ve bulanıklık izlendi. En düşük engelleyici derişim, hiç hidroksisinamik asit içermeyen ve bakteri içeren (+) denetim tüpünde bulanıklık görüldüğünde belirlendi; hiç bakteri içermeyen tüpler, bulanıklık oluşturmaması beklenen ikinci bir (-) denetim olarak gözlemlendi.

Bakterileri öldürücü en düşük derişim (Minimum bakterisidal konsantrasyon=MBK)

En düşük engelleyici derişim çalışmasından sonra, bakteri büyümesi görülmeyen tüplerin her birinden $10 \mu \mathrm{l}$ alınıp Helicobacter Columbia Agar'a ekildi ve petriler, mikroaerofilik koşullarda, $37^{\circ} \mathrm{C}$ 'de gece boyu bekletildi; kimyasallardan, bakterileri tümüyle öldüren en düşük derişim belirlendi.

\section{Üreaz engelleme deneyi}

Ferulik asit, kafeik asit, p-kumarik asit ve sinapik asidin $H$. pylori'nin ürettiği üreaz enzimleri üzerindeki doğrudan engelleyici etkisi olup olmadığı Helicheck (SALUBRIS, Türkiye) kullanılarak araştırıldı. Üreaz enzimi varlığında, Helichek'te var olan pH ayıracı sayesinde renk sarıdan mora dönmektedir; bu parçalanma ürünü olan amonyağın oluşması ile ilgilidir (27). Bu temel ilke kullanılarak H. pylori, $10 \%$ FBS (GIBCO) ve $1 \times$ vankomisin (Vancotek, 
Koçak İlaç, Türkiye) içeren Brucella Broth (Oxoid) içerisinde $37,{ }^{\circ} C^{\prime}$ de, 24 saat büyütüldü ve tüpler santrifüjlenerek üst sıvı uzaklaştıııldı. Bakteriler, üç kez PBS tamponu ( $\mathrm{pH}$ $7,4)$ ile yıkanarak üst sıvıda olabilecek tüm enzimler uzaklaştırıldı. Bakteriler, PBS içerisinde, hidroksisinamik asit türevlerinin son derişimi $512 \mu \mathrm{g} / \mathrm{ml}$ olacak şekilde, oda stcaklığında, 20 dakika bekletildi ve bakteri asıltısı (süspansiyonu) üreaz enzim etkinliğinin denenmesi için Helicheck olarak adlandırılan H. pylori'ye özgü, üreaz aktivitesinin ortamda gerçekleştiğinde renk değişikliği gösteren besiyerine aktarıldı. Nükleotid salınım deneyleri spektrofotometrik ölçümler yapılarak gerçekleştirildi.

Hidroksisinamik asitler ile hiçbir işleme uğramayan bakteriler de aynı şekilde (-) denetim olarak kullanıldı. Üreaz enzim etkinliğinin varlığı veya yokluğu, renk değişiminin var veya yok olması şeklinde olarak belirlendi.

\section{Nükleotid salınım deneyi}

Hidroksisinamik asit türevlerinin, bakteri zarlarının geçirgenliği üzerindeki etkilerinin anlaşılması için nükleotid salınım deneyi yapıldı. Bu deneyin esası, denenen kimyasalların, bakteri zarında bir hasara yol açıp açmadığının hücrelerden salınan nükleotidlerin spektroforometrik olarak ölçülmesi ile ilgilidir (28). Bu amaçla, H. pylori, 10 \%FBS ve $1 \times$ vankomisin içeren Brucella Broth (Oxoid) içerisinde $37^{\circ} \mathrm{C}^{\prime} \mathrm{de}, 24$ saat büyütüldü ve tüpler santrifüjlenerek üst sıvı uzaklaştırıldı. Bakteriler, üç kez PBS tamponu (pH 7,4) ile yıkanarak üst sıvıdaki tüm nükleotidler uzaklaştırıldı ve son olarak, PBS içerisinde, hidroksisinamik asit türevlerinin son derişimi $512 \mu \mathrm{g} / \mathrm{ml}$ olacak şekilde, oda sıcaklığında, 20 dakika bekletildikten sonra 5000xg'de üç dakika santrifüjlendi. Üst sıvının 260 nm'de soğurum (A260) değeri ölçüldü. Kimyasallarla hiçbir işleme uğramayan bakteriler ve DMSO, (-) denetim olarak kullanıldı. Verilerin çözümlemesi, GraphPad Prism 6 yazılımı kullanılarak yapıldı.

\section{Sonuçlar}

Birçok bitki, sebze ve meyvelerde bulunan ve antioksidan özellikleri nedeni ile çeşitli hastalıklara ve yaşlanmaya karşı koruduğu bilinen hidroksisinamik asit türevleri vücudu serbest radikallerin zararlı etkilerinden korumanın yanında antimikrobiyal etkileri nedeni ile saflaştırılarak elde edilen özütleri de birçok enfeksiyon etkenine karşı kullanılmaktadır. Dünyada insanların ortalama \%50'sinin midesinde kolonize oldugu tahmin edilen $\mathrm{H}$. pylori'nin tedavisi için, diğer mikroorganizmalara karşı olan etkisi bir seçenek olarak ortaya çıkan hidroksisinamik asit türevlerinden bazılarının H. pylori üzerindeki etkisi ve etki mekanizmaları bu çalışma ile anlaşılmaya çalışılmıştır.

\section{En düşük önleyici derişim}

Denenen hidroksisinamik asit türevlerinin $H$. pylori'yi engelleyici en düşük derişimi $64 \mu \mathrm{g} / \mathrm{mL}$ olarak bulunmuştur (Tablo 2).

\section{Bakterileri öldürücü en düşük derişim}

Denenen hidroksisinamik asit türevlerinin H. pylori'yi öldürücü en düşük derişimi 128 $\mathrm{g} / \mathrm{mL}$ olarak bulunmuştur (Tablo 3).

Mevcut çalışma ile hidroksisinamik asit türevleri, önemli bir H. pylori karşıtı etkiye sahip olduğu gösterilmiştir: Engelleyici en düşük derişimi $64 \mu \mathrm{g} / \mathrm{mL}$ ve bakterileri öldürücü en düşük derişimi $128 \mu \mathrm{g} / \mathrm{mL}$. Bu sonuçlar, $H$. pylori'nin artmış ilaç direncine karşı, bu doğal ürünlerin birer seçenek olabileceğine dair umut vericidir ve gelecekte, canlı-içi çalışmaları da kapsayacak şekilde yeni deneyler, H. pylori enfeksiyonlarının tedavisinde, bu doğal ürünlerin yeni ilaçlar olarak kullanılabilir olup olamayacağını göstermesi bakımından önemli olacaktır.

Tablo 2. En düşük engelleyici derişim (MiK) sonuçları

\begin{tabular}{lc} 
Kimyasallar & $\begin{array}{c}\text { En düşük engelleyici derişim } \\
(\boldsymbol{\mu} \mathbf{g} / \mathbf{m L})\end{array}$ \\
\hline Sinapik asit & 64 \\
Kafeik asit & 64 \\
Ferulik asit & 64 \\
p-Kumaric asit & 64
\end{tabular}

Tablo 3. Bakterileri öldürücü en düşük derişim (MBK) sonuçları

\begin{tabular}{lr} 
Kimyasallar & $\begin{array}{r}\text { Bakterileri öldürü } \\
\text { derişim }(\boldsymbol{\mu g} /\end{array}$ \\
\hline Sinapik asit & 128 \\
Kafeik asit & 128 \\
Ferulik asit & 128 \\
p-Kumaric asit & 128
\end{tabular}

\section{Üreaz engelleme deneyi}

Kafeik asit, ferulik asit, p-kumarik asit ve sinapik asidin $H$. pylori'nin üreaz enziminin etkinliğini engelleyip engellemediği araştırıldı ve bu amaçla renk değşimine dayalı bir yöntemi esas alan Helicheck kullanıldı. Hidroksisinamik asit türevleri ile buluşturulmamış bakteriler ile kıyaslandığında, bu kimyasallara maruz bırakılmış H. pylori tüpleri arasında, herhangi bir renk farklılığı gözlenmemiştir: Tüm tüplerde, sarıdan mora dönüşüm eşit miktarda gerçekleşmiştir (Şekil 2). Bu sonuçlara göre, denenen derişimlerdeki hidroksisinamik asit türevlerinin, $H$. pylori bakterisinin üreaz enziminin etkinliği üzerinde bir etkiye sahip değildir. 


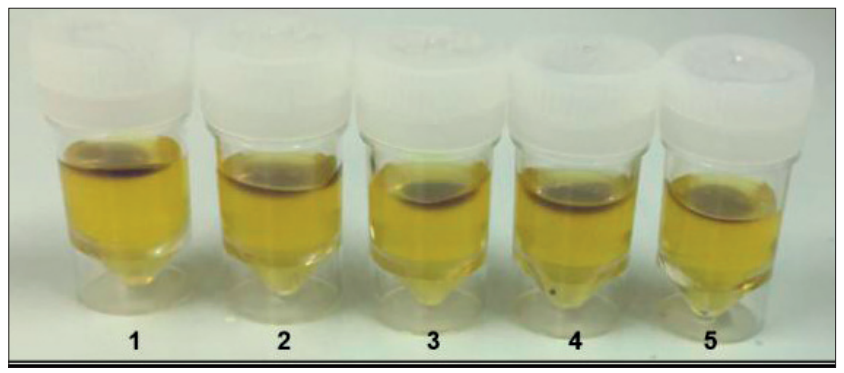

Şekil 2. Üreaz etkinliğini engelleme deneyi.

Nükleotid salınım deneyi

Hidroksisinamik asit türevlerinin bakteri zarının geçirgenliğini değiştirip değiştirmediğini belirlemek için nükleotid salınım deneyi yapıldı.

260 nm'deki soğurum değerleri karşılaştırıldığı da hidroksisinamik asit türevlerine bağlı olarak zardan geçerek hücre dışına salınan saptanabilir düzeyde nükleotid bulunamadı (Şekil 3).

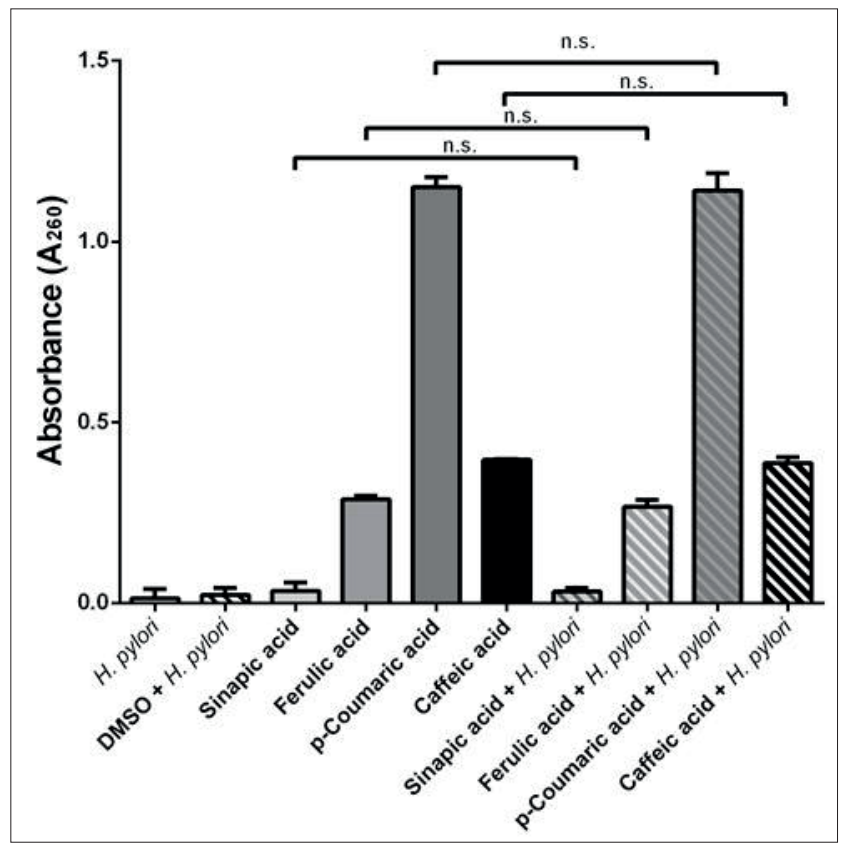

Şekil 3. Nükleotid salınım deneyi

Sonuç olarak, hidroksisinamik asit türevlerinden ferulik asit, kafeik asit, p-kumarik asit ve sinapik asidin H. pylori karşıtı etkilere sahip olduğu gösterildi. Bu kimyasalların, bakterinin hücre zarının geçirgenliğini değiştirdiğine dair nükleotid salınımı timeline dayanan deneyde, kimyasallara maruz bırakılmayan denetim grubuna kıyasla saptanabilir bir fark gözlenmemiştir. Ayrıca, uygulanan mevcut yöntem ile bakterinin enzimini etkilediğini gösteren bir bulgu elde edilmemiştir. Gelecekte yeni ek çalışmalar, bu kimyasalların, H. pylori üzerindeki karşıt etkinliğin işlergesini (mekanizmasını) anlamamıza yardım edebilecektir.

\section{Tartışma}

H. pylori enfeksiyonları, dünya nüfusunun yaklaşık yarısını etkilemektedir ve tedavisi, ilaç direnci, ilaçların yan etkileri ve pahalııı̆ı nedeniyle zordur. Günümüzde, tedavide, clarithromycin, amoxicillin, metronidazole, levofloxacin, tetracycline ve rifabutini içeren yalnızca altı farklı antibiyotiğin çeşitli bileşkeleri kullanılabilmektedir. Bu bağlamda, hem farmokolojik tedavilerle kıyaslandığında düşük maliyetli oluşları hem de düşük toksisite ve daha az yan etkilere sahip oluşları dikkate alındığında, doğal ürünlerin keşfi, bu tedavilerde yeni seçenekler oluşturabilecektir.

Hidroksisinamik asitler, meyve, sebze ve yemeklik mantar gibi birçok bitkilerde bulunan fenolik bileşiklerdendir ve kafeik asit, ferulik asit, p-kumarik asit, sinapik asit, klorojenik asit, rosmarinik asit gibi türleri mükemmel farmosotik potensiyele sahiptir ve anti-inflamatuvar, antioksidan, antimikrobiyal, antikoagülan, antitumor, antiviral etkinlik göstermektedirler.

Bugüne kadar, hidroksisinamik asit türevlerinin, birçok bakteriye karşı etkinlikleri gösterilmiş olsa da bildiğimiz kadarıyla, H. pylori için böyle bir sonuç henüz yayımlanmıştır (29). Dünyadaki en yaygın enfeksiyonlardan birinin kaynağı olan H. pylori enfeksiyonunun enfeksiyöz bir hastalık olarak ele alınıp tedavi edilmesi oldukça önemlidir. Antibiyotik tedavisinin yalnız başına kullanıldığı zaman yeterli eradikasyon sağlanamadığı yapılan kaynak çalışmaları ile de gösterilmiştir. Antibiyotik tedavisinin yetersiz kaldığı durumlarda alternatif tedavi yöntemleri tercih edilmektedir. Bu nedenler doğrultusunda birçoğu günlük hayatta tüketilen meyve ve bitkilerin içeriğinde yer alan hidroksisinamik asit türevlerinin, meyve ve bitkilerden özütlenerek saf halde yoğunlaştırılması ile $H$. pylori ye karşı antimikrobiyal etkinliğinin gösterilmesi oldukça önem taşımaktadır. Etki mekanizmalarının aydınlatılması ve etkinliklerininde geliştirilmesi için yapılacak olan ek çalışmalar sayesinde hidroksisinamik asit türevlerinin $H$. pylori enfeksiyonunun tedavisinde kullanılacak alternatif bir yöntem haline gelecektir.

Sunulan bu çalışma, hidrokissinamik asit türevlerinden kafeik asit, ferulik asit, p-kumarik asit ve sinapik asidin $H$. pylori karşıtı etkisi ile ilgili bilim yazınındaki ilk çalışmadır.

\section{Teşekkür}

Bu çalışma Acıbadem Mehmet Ali Aydınlar Üniversitesi'nin Bilimsel Araştırma Proje Fonu (ABAPKO Proje numarası: 2017/01/07) tarafından desteklenmiştir. Zürih Üniversitesi, Moleküler Kanser Araştırma Enstitüsü’nden Prof. Dr. Anne Mueller'e hediye ettiği H. pylori için teşekkür ederiz. 


\section{Kaynaklar}

1. Sipponen $P$, Hyvärinen $H$. Role of Helicobacter pylori in the Pathogenesis of Gastritis, Peptic Ulcer and Gastric Cancer. Scand J Gastroenterol 1993;28:196:3-6. [CrossRef]

2. Correa P. Helicobacter pylori and gastric carcinogenesis. Am J Surg Pathol 1995;19:37-43.

3. Ceylan A, Kırımi E, Tuncer O, Türkdoğan K, Arıyuca S, Ceylan N. Prevalence of Helicobacter pylori in Children and Their Family Members in a District in Turkey. J Health Popul Nutr 2007;25:4:422-7. Erişim: https://www.ncbi.nlm.nih.gov/pmc/articles/PMC2754017/

4. Maurizio ZR, Rabitti S, Eusebi LH, Bazzoli F. Treatment of Helicobacter pylori infection: A clinical practice update. Eur J Clin Invest 2018;48:e12857. [CrossRef]

5. Alba C, Blanco A, Alarcon T. Antibiotic resistance in Helicobacter pylori. Curr Opin Infect Dis 2017;30:5:489-97. [CrossRef]

6. Testerman TL, McGee DJ, Mobley HLT. Adherence and Colonization, Chap. 4. In: Mobley HLT, Mendz GL, Hazell SL, editors. Helicobacter pylori: Physiology and Genetics. Washington (DC): ASM Press; 2001.

7. Hassan S, Šudomová M. The Development of Urease Inhibitors: What Opportunities Exist for Better Treatment of Helicobacter pylori Infection in Children? Children 2017;4:1. [CrossRef]

8. Prior RL, Cao G, Martin A, Sofic E, McEwen J, O'Brien C, et al. Antioxidant capacity as influenced by total phenolic and anthocyanin content, maturity, and variety of Vaccinium species. J Agric Food Chem 1998;46:2686-93. [CrossRef]

9. Heinonen IM, Meyer AS, Frankel EN. Antioxidant activity of berry phenolics on human low-density lipoprotein and liposome oxidation. J Agric Food Chem 1998;46:4107-12. [CrossRef]

10. Sellappan S, Akoh CC, Krewer G. Phenolic compounds and antioxidant capacity of Georgia-grown blueberries and blackberries. J Agric Food Chem 2002;50:2432-8. [CrossRef]

11. Borowska J, Szajdek A. Antioxidant activity of berry fruits and beverages. Pol J Natl Sci 2003;14.

12. Moyer RA, Hummer KE, Finn CE, Frei B, Wrolstad RE. Anthocyanins, phenolics, and antioxidant capacity in diverse small fruits:Vaccinium, Rubus, and Ribes. J Agric Food Chem 2002;50:519-25. [CrossRef]

13. Benvenuti S, Pellati F, Melegari M, Bertelli D. Polyphenols, anthocyanins, ascorbic acid, and radical scavenging activity of Rubus, Ribes, and Aronia. J Food Sci 2004;69:FCT164-9. [CrossRef]

14. Wang SY, Stretch AW. Antioxidant capacity in cranberry is influenced by cultivar and storage temperature. J Agric Food Chem 2001;49:969-74. [CrossRef]

15. Zheng W, Wang SY. Oxygen radical absorbing capacity of phenolics in blueberries, cranberries, chokeberries, and lingonberries. J Agric Food Chem 2003;51:502-9. [CrossRef]

16. De Ancos B, González EM, Cano MP. Ellagic acid, vitamin C, and total phenolic contents and radical scavenging capacity affected by freezing and frozen storage in raspberry fruit. J Agric Food Chem 2000;48:4565-70. [CrossRef]
17. Anttonen MJ, Karjalainen RO. Environmental and genetic variation of phenolic compounds in red raspberry. J Food Comp Anal 2005;18:759-69. [CrossRef]

18. Wada L, Ou B. Antioxidant activity and phenolic content of Oregon caneberries. J Agric Food Chem 2002;50:3495-500. [CrossRef]

19. Proteggente AR, Pannala AS, Paganga, G, Buren, LV, Wagner, E, Wiseman $\mathrm{S}$, et al. The antioxidant activity of regularly consumed fruit and vegetables reflects their phenolic and vitamin C composition. Free Radic Res 2002;36:217-33. [CrossRef]

20. Skupień K, Oszmiański J. Influence of titanium treatment on antioxidants content and antioxidant activity of strawberries. Acta Sci Pol Tech Aliment 2007;6:83-94. Erişim: https://www.food. actapol.net/pub/8_4_2007.pdf

21. Zheng, Y, Wang, SY, Wang, CY, Zheng W. Changes in strawberry phenolics, anthocyanins, and antioxidant capacity in response to high oxygen treatments. LWT - Food Sci Tech 2007;40:49-57. [CrossRef]

22. Barış Tuncel N, Yılmaz N. Kaz Dağları'ndan Toplanan Bazı Bitkilerin Fenolik Asit Kompozisyonlarının Yüksek Performanslı SıVı KromatografisindeBelirlenmesi. AkademikGıda 2010;8:18-23.Erişim: http://www.academicfoodjournal.com/archive/2010/3/18-23.pdf

23. Kafarski $P$, Talma M. Recent advances in design of new urease inhibitors: A review. J Adv Res 2018;13:101-12. [CrossRef]

24. Cheng JC, Dai F, Zhou B, Yang L, Liu ZL. Antioxidant activity of hydroxycinnamic acid derivatives in human low density lipoprotein: Mechanism and structure-activity relationship. Food Chem 2007;104:1:132-9. [CrossRef]

25. Alam MA, Subhan N, Hossain H, Hossain M, Reza HM, Rahman MM, Ullah MO. Hydroxycinnamic acid derivatives: a potential class of natural compounds for the management of lipid metabolism and obesity. Nutr Metab 2016;13:27. [CrossRef]

26. Kuczkowiak U, Petereit F, Nahrstedt A. Hydroxycinnamic Acid Derivatives Obtained from a Commercial Crataegus Extract and from Authentic Crataegus spp. Sci Pharma 2014;82:4:835-46. [CrossRef]

27. Calik Z, Karamese M, Acar O, Aksak SK, Dicle Y, Albayrak F, et al. Investigation of Helicobacter pylori antigen in stool samples of patients with upper gastrointestinal complaints. Braz J Microbiol 2016;47:167-71. [CrossRef]

28. Perumal S, Mahmud R, Ismail S. Mechanism of Action of Isolated Caffeic Acid and Epicatechin 3-gallate from Euphorbia hirta against Pseudomonas aeruginosa. Pharmacogn Mag 2017;13:S311-5. [CrossRef]

29. Taofiq O, González-Paramás AM, Barreiro MF, Ferreira IC. Hydroxycinnamic Acids and Their Derivatives: Cosmeceutical Significance, Challenges and Future Perspectives, a Review. Molecules 2017;22:281. [CrossRef] 